\title{
TESIS SOBRE FERRAJOLI *
}

\author{
Manuel Atienza **
}

Universidad de Alicante

RESUMEN. El autor considera la obra de FERRAJOLI, por su rigor intelectual y sus profundas implicaciones prácticas, como un hito fundamental en la cultura jurídica contemporánea. Critica, sin embargo, su anclaje en el positivismo jurídico y el no cognoscitivismo ético. Y termina sugiriendo la necesidad de transformar la teoría en el sentido de superar esos dos obstáculos, lo que haría posible «integrarla en el contexto de una concepción amplia y unitaria de la razón práctica».

Palabras clave: FERRAJOLI, positivismo jurídico, no cognoscitivismo ético.

ABSTRACT. The author considers FERRAJOLI's work to represent a milestone in contemporary legal culture due to its intellectual rigour and its profound practical implications. However, he criticizes the fact that it is based on legal positivism and ethical noncognitivism. The author finishes by pointing to the need to transform the theory, seeking to overcome these two obstacles, which would make possible «its incorporation into the context of a broad and unitary conception of practical reason».

Keywords: FERRAJOLI, legal positivism, ethical noncognitivism.

* Fecha de recepción: 1 de diciembre de 2008. Fecha de aceptación: 18 de diciembre de 2008.

** Presento aquí de manera muy sintética lo que fue mi contribución en el seminario de Brescia. He tenido muy en cuenta para ello un comentario a la obra de FERRAJOLI que escribí en ocasión de otro seminario celebrado en Madrid (unos meses antes que el de Brescia), al igual que la respuesta de FERRAJOLI a las críticas que entonces le dirigía; véase L. FERRAJOLI, J. J. Moreso y M. ATIENZA, 2008: La teoría del Derecho en el paradigma constitucional, Madrid: Fundación Coloquio Jurídico Europeo. 


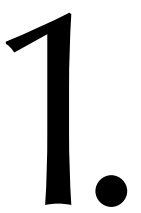

Los filósofos del Derecho del mundo latino suelen escribir obras en las que comentan y discuten lo que sus colegas de otros ámbitos culturales (antes alemanes, ahora anglosajones) han pensado sobre el Derecho, sobre la justicia, sobre la democracia, sobre los derechos humanos... FERRAJOLI ha roto con esa tradición y se ha atrevido a construir una teoría, si no de espaldas, al menos que mira tan sólo ocasionalmente y desde cierta distancia, a las modas iusfilosóficas imperantes entre nosotros en los últimos tiempos. Sólo por ello merecería ya un gran reconocimiento por parte de quienes pensamos que la teoría del Derecho del mundo globalizado debería «equilibrarse», en el sentido de atribuir un mayor peso a la cultura jurídica de los países latinos.

2. Pero la extraordinaria influencia que su obra está teniendo en el mundo latino (de Europa y América) tiene que ver, sobre todo, con el hecho de que se trata de una teoría de gran rigor intelectual y profundas implicaciones prácticas y cuyos destinatarios no son exclusivamente otros teóricos del Derecho, sino cualquier jurista que se tome en serio su profesión. El objetivo último de FERRAJOLI, el ideal regulativo que propone a los juristas, viene a ser éste: debe procurarse que el Derecho (nuestros Derechos del Estado constitucional) cumpla(n) sus promesas en relación con los derechos fundamentales. La obra de FERRAJOLI está, pues, orientada a potenciar el lado emancipador del Derecho, pero sin olvidar tampoco (y de ahí su dimensión crítica) que en su funcionamiento real el Derecho no siempre cumple esa función.

3. Sin embargo, es posible adherir plenamente a esos objetivos y pensar que los mismos podrían alcanzarse en una forma más plena si en la teoría se introdujeran algunos cambios de cierta relevancia. La obra de FERRAJOLI (en especial, Principia iuris) se asemeja a una máquina formidable en la que, de forma un tanto sorprendente, se han utilizado algunas piezas obsoletas y que dificultan su buen funcionamiento.

4. FERRAJOli ha mostrado la existencia de una doble articulación en el plano de la validez interna del Derecho de los Estados constitucionales y ha extraído, a partir de ahí, importantes consecuencias teóricas y prácticas: el Derecho formalmente vigente puede ahora ser considerado inválido desde parámetros establecidos por el propio Derecho (sin acudir a instancias - morales- externas al mismo), de manera que la dogmática jurídica y la jurisdicción adquieren una nueva dimensión crítica; ya no es la política lo que prima sobre el Derecho, sino que el Derecho (los derechos fundamentales recogidos en la Constitución) marca el límite de la política; etc. ¿Pero por qué el empeño en considerar que el nuevo paradigma —el del constitucionalismo jurídico- no sólo es compatible con el positivismo jurídico, sino que significa su completo desarrollo?

5. La razón fundamental por la que FERRAJOLI defiende la anterior tesis parece ser ésta: el positivismo jurídico implica la separación entre el punto de vista (jurídico) interno y el punto de vista (ético-político) externo y el primado del segundo sobre el primero; eso evitaría confusiones conceptuales y conjuraría el riesgo de sacralizar el Derecho positivo. Así pues: claridad conceptual y capacidad crítica. Ahora bien, una teoría no positivista del Derecho no tiene por qué llevar a identificar el Derecho con la justicia y nada impide tampoco que se pueda hablar desde ella de «Derecho injusto». Y en cuanto a su capacidad crítica, no se ve por qué la misma ha de quedar disminuida por el hecho de reconocer que además de una justicia (o moralidad) externa al Dere- 
cho existe también una de carácter interno. Otra cosa es que muchos conflictos que se planteaban antes como contradicciones entre el Derecho y la moral hayan pasado a ser tematizados (precisamente como consecuencia del desarrollo del Estado constitucional) como problemas de interpretación — de interpretación constitucional- e internos, por tanto, al Derecho.

6. La diferencia entre la concepción positivista de FERRAJOLI y una concepción no positivista como la que en los últimos tiempos han defendido autores como DwORKIN, NINO o ALEXY no radica en que estos últimos ignoren la diferencia entre el Derecho y la moral o en que su orientación sea «tendencialmente» iusnaturalista. Se sitúa en otro lugar. Estos últimos, en efecto, consideran que el Derecho tiene, además de un componente autoritativo (el único que FERRAJOLI parece tener en cuenta), otro de carácter valorativo. Eso es lo que le lleva a DwORKIN a considerar el Derecho como una práctica interpretativa en la que los fines y valores de la misma juegan un papel determinante; a ALEXY, a identificar en el concepto de Derecho un elemento de idealidad, una «pretensión de corrección»; y a NINO, a defender la tesis de que las normas jurídicas no suponen por sí mismas razones justificativas autónomas, de manera que el razonamiento jurídico debe ser considerado como un razonamiento abierto hacia las razones morales. Lo que se sigue de ahí es que el Derecho no puede ser entendido exclusivamente como un sistema de normas, sino también como una práctica social.

7. FERRAJOLI, al considerar el Derecho esencialmente como un conjunto de normas, de reglas, tiende a pensar que en la aplicación del Derecho lo que existe es algo así como subsunción y discrecionalidad, al tiempo que es notablemente escéptico a propósito de la ponderación. $\mathrm{O}$, dicho de manera quizás más matizada, dado que, en su opinión, no hay una diferencia cualitativa entre reglas y principios, no puede haber tampoco una diferencia relevante en cuanto a su utilización para resolver problemas prácticos. El resultado es una teoría poco desarrollada de la interpretación y de la argumentación jurídicas y una carencia de instrumentos teóricos con los que poder dar cuenta de un aspecto importante de nuestra práctica jurídica: la que concierne a los casos difíciles en materia de derechos fundamentales.

8. Otra consecuencia de lo anterior consiste en identificar los derechos fundamentales con normas jurídicas. Para FERRAJOLI, en cuanto concepto de la teoría del Derecho, los derechos fundamentales son los derechos subjetivos atribuidos a todos en cuanto ciudadanos, en cuanto personas o en cuanto personas con capacidad de obrar; la bondad de ese concepto dependería de su capacidad para dar cuenta de sus usos dogmáticos. Pero no parece que eso se logre con tal definición. También en el uso dogmático, los derechos son considerados como razones, como algo que está más allá de las normas, es decir, como valores (término que no aparece en el minucioso índice de materias de Principia iuris) que justifican que, para su protección, se establezcan normas de tipos distintos: regulativas y constitutivas, reglas y principios, etc.; incluso para conocer lo que son los derechos fundamentales (y no sólo para identificar cuáles son) necesitamos tanto el concepto de norma como el de valor. Por eso, ningún dogmático consideraría aceptable la afirmación de que «si fuera establecido como universal un derecho absolutamente fútil, como por ejemplo el derecho a ser saludados por la calle por los propios conocidos o el derecho a fumar, el mismo sería un derecho fundamental»; no la consideraría aceptable porque del concepto de derecho fundamental forma parte ne- 
cesariamente la idea de valor, la idea de que los derechos fundamentales se tienen (o se establecen) para dar cumplimiento a valores de especial importancia.

9. Por eso, también, resulta artificioso separar la noción formal (de teoría del Derecho) y la noción material (de filosofía ético-política) de derechos fundamentales. La explicación (aparte de que la «ideología de la separación» sea un rasgo típico del positivismo) se encuentra, probablemente, en su ambicioso proyecto de construir una teoría axiomatizada del Derecho. Pues la teoría jurídica de FERRAJOLI no es sólo puramente formal, sino también considerablemente estipulativa, a fin de que sus conceptos puedan ser presentados en forma axiomática. El problema es que con ello se pone en serio riesgo la practicabilidad de esa teoría: no sólo por la dificultad intrínseca de asimilar un número tan impresionante de postulados, definiciones y teoremas, sino también por el grado de artificiosidad de la construcción.

10. FERRAJOLI afirma que los derechos fundamentales no son más que convenciones jurídicas, desligadas de cualquier pretensión de objetividad de carácter moral. ¿Pero se puede, a partir de una concepción relativista y no cognoscitivista de la ética, fundamentar que la noción ético-política de «derechos fundamentales» se identifica con los valores de igualdad, paz, democracia y tutela de los más débiles? ¿No tienen esos valores un carácter objetivo y universal?

11. FERRAJOLI ha interpretado el constitucionalismo de nuestros días en clave positivista y relativista. De lo que se trata es de transformar esa teoría en el sentido de superar los dos anteriores postulados, lo que haría posible integrarla en el contexto de una concepción amplia y unitaria de la razón práctica. 